\title{
Effect of Designed Protective Clothing on Physiological Workload of Pesticide Application Activity
}

\author{
Madhuri Kulkarni", Jayashree Suryatal and Sunita Kale \\ Department of Community Science, VNMKV, Parbhani-431 402, M.S., India \\ *Corresponding author
}

Keywords

Protective clothing, Pesticide

application,

Physiological work load

Article Info

Accepted:

18 March 2021

Available Online:

10 April 2021
The present study was carried out in selected six villages namely Nandkheda, Daithna, Katneshwar, Dohra, Hatta, Jawala of Parbhani and Hingoli districts of Marathwada region of Maharashtra State. A sample of 30 pesticide applicators from the age group of 25 - 45 years who were involved in pesticide application activity since 5 years was selected for on field trials of pesticide application activity by wearing protective clothing. designed by Department of Clothing and Textiles, College of Community Science, VNMKV Parbhani and Protective clothing available in local market. On the whole it can be concluded that the physiological cost of pesticide application was more when applicants wore marketed protective clothing than designed protective clothing. Statistical analysis revealed significant results, which indicated that the average working heart rate, average recovery heart rate, average peak heart rate and average total cardiac cost of work was reduced significantly when the task of pesticide application was carried out in designed protective clothing.

\section{Introduction}

Pesticide application plays an important role in pest management. Proper technique of application of pesticide and the equipment used for applying pesticide are vital to the success of pest control operations. The importance of taking safety precautions while handling and applying pesticides is often underestimated. An effort must be made to give a comprehensive account of the various aspects of the safe use of pesticides, especially for staff operating spraying equipment and handling chemicals (Pal and Dasgupta, 1996). Personal Protective Equipment prevents pesticides from coming in contact with the body or clothing. These also protect the eyes and prevent the inhalation of toxic chemicals. Personal safety gear includes clothing that covers the arms, legs, nose, and head. Gloves 
and boots are used to protect the hand and feet, and hats, helmets, goggles, and face masks to protect the hair, eyes, and nose.

Pesticides can enter the body four ways i.e. through skin, eyes, mouth and lungs. Skin contact is the most common cause of pesticide poisoning for applicators and some pesticides enter the body through the skin quite readily. Overalls made of cotton are the best but should not be worn without additional protective clothing. When there is a chance of contacting wet spray, large sleeves with cuffbuttons, and pants with buttons at the bottom offer good protection. Waterproof rubber or plastic aprons are effective. They should be long enough to protect the general clothing. The use of gloves reduces the risk of dermal exposure in the hand region. At the time of mixing, pesticides are more concentrated and the likelihood of injury is increased during this time. Hence it is best to avoid direct contact with pesticides by wearing the proper Personal Protective Equipment (PPE) as specified on the label of the pesticide you intend to use. (https://www.pesticides.montana.edu/referenc e/ppe.html-23-2-2021)

Wearing protective clothing when applying pesticides can reduce the risk of pesticide poisoning because it reduces the chance of exposure. Many pesticide labels instruct the user to wear personal protective equipment (PPE). PPE is clothing and devices that protect the body from contact with pesticides or pesticide residues. Pesticides covered by the newly revised Worker Protection Standards must now list PPE requirements more clearly on their labels.

Protective clothing is an important line of defense for the workers in hazardous occupations. Even though workers generally recognize the need for protective clothing, they often experience problems with the sizing, design and function of the clothing as well as experiencing discomfort. The workers may not wear the clothing properly or at all. Even when garments are worn as recommended, design flaws may result in problems that expose workers to environmental hazards (Boorady et al., 2009).

New tools and techniques with greater reliabilities than those already existing are needed to protect the potential hazard of pesticides and thus contribute to reduction of the adverse effects on human health. Hence there is need to find, tool and safety measures, precautions while applying pesticides to avoid health hazards. Keeping in view of these facts of pesticide application the designed protective clothing by Department of Textile and Apparel Designing, College of Community Science was tested for pesticide application activity. In the present study the pesticide application by using marketed protective clothing and with use of designed protective clothing is compared in terms of physiological cost, comfort level and utility perception.

\section{Materials and Methods}

\section{Locale of the study}

The present study was carried out in selected six villages namely Nandkheda, Daithna, Katneshwar, Dohra, Hatta, Jawala of Parbhani and Hingoli districts of Marathwada region of Maharashtra State

\section{Selection of the sample}

A purposive random sampling method was followed to select 30 pesticide applicators from the age group of 25 - 45 years who were involved in pesticide application activity since 5 years. The selected pesticide applicators were healthy and without any physical deformities and illness. 
Developing questionnaire and observation schedule

The questionnaire was developed to collect the information on selected variables related to study Information was collected through personal interview method. Observation schedule for noting down the selected physiological variables such as heart rate, The information was recorded through direct observation and calculations.

\section{Tools and techniques used for data collection}

Experiment of pesticide application was carried out with two types of protective clothing i.e. Designed by Department of Clothing and Textiles, College of Community Science, VNMKV Parbhani and Protective clothing available in local market.

The material used for designed protective clothing was water resistant so that the material will not permit pesticide spray to pass through but will be permeable to air. The protective clothing was inner-lined with soft, water absorbent cotton fabric so that it will absorb any splash of pesticide if in case it gets inside and will be comfortable to the wearer. It was $a$ one piece protective clothing covering pesticide applicator from neck to full length (below knee).

Full sleeves provided with elastic at wrist level to protect complete arms and was provided with Polo collar to protect neck from pesticide vapours. Front opening provided with Velcro at regular distance so that proper ventilation can be provided and also easy for closing the garment. A cap with attachment of fabric mask to protect nose from pesticide inhalation was used with this protective clothing. It also protected the mouth of pesticide applicator. For easy respiration, the mask made up of fine muslin cloth attached to the strip of hosiery fabric which is ultimately attached to the cap with the help of studs was used.

Protective clothing available in local market consisted of a full length pant covering the lower body of the pesticide applicator, from waist to ankle and made up of plastic material. Pant had elastic at waist but not at bottom and a jacket of full sleeves with length up to wrist level provided with no elastic at wrist level.

The jacket was with Shirt collar and front opening with zip. It is provided with Beak Mask of Needle punched non-woven material and plastic hand gloves.

\section{Data Collection through on field trials}

A group of 30 pesticide applicators was selected for on field trials of protective clothing. Pesticide applicators were given both the type of protective clothing for on field trials. Each pesticide applicator had minimum three trials of pesticide application activity by wearing both types of protective clothing.

\section{Determination of physiological cost of pesticide application activity}

Heart rate method was used to estimate the physiological cost of pesticide application activity. (Varghese et al., 1994)

\section{Average working heart rate (b.m $\left.{ }^{-1}\right)$ (AWHR)}

Working heart rate was taken till the completion of pesticide application both carried out in marketed and designed protective clothing.

Average peak heart rate (b.m $\left.{ }^{-1}\right)$ (APHR)

Peak heart rate was noted down while performing the pesticide application activity. 


\section{Average recovery heart rate}

Recovery heart rate of pesticide applicants is recorded with the help of heart rate monitor by allowing the worker to record after pesticide application activity.

Average and peak energy expenditure $\left(K_{j} . \mathrm{m}^{-1}\right)$ (AEE and APEE)

It was calculated by using the formula.

$\mathrm{EE}\left(\mathrm{Kj} . \mathrm{m}^{-1}\right)=0.159 \mathrm{X}$ heart rate $\left(\mathrm{bm}^{-1}\right)-8.72$

Total cardiac cost of work (TCCW) (b.m-1)

Total cardiac cost of work was calculated by using the following formula:

TCCW $=$ cardiac cost of work + cardiac cost of recovery.

Where,

Cardiac cost of work $=($ Average working heart rate - Average resting heart rate $\mathrm{X}$ duration)

Cardiac cost of recovery $=$ (Average recovery heart rate - Average resting heart rate $\mathrm{X}$ duration)

Physiological cost of work (PCW) (beats)

It was calculated by using the following formula

Physiological cost of work (PCW)

$=\underline{\text { Total cardiac cost of work }}$

Total time of work

Assessment of comfort level of designed and marketed protective clothing.

Statements related to comfort level were developed by surveying pesticide applicators and in consultation with experts. The scale consisted total 24 statements 12 positive and
12 negative regarding the aspects of comfort feeling. The responses on three points were collected from pesticide applicators. The rating of three point was strongly agree, agree and disagree. The positive statements were rated in the sequence of 3,2,1 and negative statements were scored as $1,2,3$. The weighted mean score to assess comfort level was calculated by using following formula

WMS

Frequency x Weightage

Total no. of respondents (30)

Assessment of utility perception of designed and marketed protective clothing.

The utility perception of designed and marketed protective clothing was assessed by using three point scale developed by unit coordinator AICRP CT, (2010).

The scale consisted total 20 statements out of which 10 each were negatively and positively explaining the utility of protective clothing. The functional features of designed and marketed protective clothing were arranged on three point such as strongly agree, agree and disagree.

Negative statements were scored as 1, 2, 3 and positive statements were scored as $3,2,1$. Weighted mean score for utility perception was calculated by using the formula

WMS

Frequency x Weightage

Total no. of respondents (30)

\section{Statistical analysis}

The comparative analysis of designed and protective clothing was statistically tested by applying ' $\mathrm{t}$ ' test (Sharma, 2005) 


\section{Results and Discussion}

\section{General information of the selected pesticide applicators}

General information of the selected pesticide applicators is given in table 1. It is observed from the table that most of the pesticide applicators who were engaged in pesticide application activity had their monthly income between Rs.4501-6500/- (36.66\%) while 30 per cent of the pesticide applicators belonged to second and forth category of monthly income of Rs.2501-4500/- and Rs.6501-8500. Very few workers $(3.33 \%)$ had their monthly income between Rs. 500 and 2500.

From the table it is observed that the majority of the pesticide applicators $(60 \%)$ had their monthly family income between Rs.1010020000/- and 33.33 per cent of pesticide applicators had monthly family income less than Rs 10000/-.Very few families (6.66\%) had monthly income more than Rs 20,000/-.

With reference to the pesticide applicants education, it was observed that majority of the workers had secondary education (60\%) whereas 23.33 per cent of the pesticide applicators had higher secondary education. Only 6.66 per cent pesticide applicators were educated up to primary school. Majority of the pesticide applicators belonged to joint family $(63.33 \%)$ followed by nuclear family $(36 \%)$.

The percentage of the pesticide applicators having 5 to 10 members in the family was 23 , whereas 13 per cent of the pesticide applicators belonged to small family consisting 1to 4 members in family. Ten per cent of the pesticide applicators belonged to the large size family consisting more than 10 members in family. Majority of the pesticide applicators were working on own farm $(63.33 \%)$ and 36 per cent of the pesticide applicants were paid workers.
Physiological work load of pesticide application activity carried out by wearing designed and marketed protective clothing.

Physiological work load of pesticide application activity carried out by wearing designed and marketed protective clothing is presented in table no 2. It was observed from the table that average working heart rate (109 b.m- $\left.{ }^{1}\right)$, average recovery heart rate $\left(90\right.$ b.m- $\left.{ }^{1}\right)$, average peak heart rate (121), average energy expenditure $(9 \mathrm{kj}-\mathrm{m})$, average physiological cost of work (36), average peak energy expenditure $(10.5 \mathrm{kj}-\mathrm{m})$ and average total cardiac cost of work (540) was observed more when the pesticide applicants wore marketed protective clothing than the values recorded after wearing designed protective clothing.

Statistical analysis with ' $t$ ' manifested significant reduction in average working heart rate $\left(\mathrm{t}=4.2^{* *}\right)$, physiological cost of work $(\mathrm{t}$ $\left.=4^{*}\right)$ and total cardiac cost of work $\left(\mathrm{t}=2.9^{*}\right)$ of pesticide applicants when the pesticide application activity was carried out after wearing designed protective clothing.

\section{Comfort level of the marketed and designed pesticide protective clothing}

The information on comfort level of the marketed and designed protective clothing is presented in table no 3 . It is clear from the table that majority of the respondents rated medium level of comfort (1.67-2.33) for marketed (76.66\%) and designed (80\%) pesticide protective clothing. There was significant difference between the respondents who have scored less for comfort level for designed and marketed $(16.66 \%)$ pesticide protective clothing $(\mathrm{t}=2.67 *)$.

Mean score of comfort level for marketed pesticide protective clothing (1.9) was lower than the mean score of designed protective clothing (2.1). 
Table.1 General information of the selected pesticide applicants

\begin{tabular}{|c|c|c|}
\hline Attributes & Frequency & Percentage \\
\hline \multicolumn{3}{|c|}{ Monthly Income of the Respondents (Rs) } \\
\hline 500 to 2500 & 1 & 3.33 \\
\hline 2501 to 4500 & 9 & 30 \\
\hline 4501 to 6500 & 11 & 36.66 \\
\hline 6501 to 8500 & 9 & 30 \\
\hline \multicolumn{3}{|c|}{ Monthly Family Income (Rs) } \\
\hline$<10000$ & 10 & 33.33 \\
\hline 10100 to20000 & 18 & 60 \\
\hline$>20000$ & 2 & 6.66 \\
\hline \multicolumn{3}{|l|}{ Educational Level } \\
\hline Illiterates & 3 & 10 \\
\hline Primary & 2 & 6.66 \\
\hline Secondary & 18 & 60 \\
\hline Higher Secondary & 7 & 23.33 \\
\hline \multicolumn{3}{|l|}{ Type of Family } \\
\hline Joint & 19 & 63.33 \\
\hline Nuclear & 11 & 36 \\
\hline \multicolumn{3}{|l|}{ Size of Family } \\
\hline Small (1 to 4$)$ & 4 & 13.33 \\
\hline Middle (5 to 10) & 23 & 76.66 \\
\hline Large $(>10)$ & 3 & 10 \\
\hline \multicolumn{3}{|l|}{ Working Status } \\
\hline Own farm & 19 & 63.33 \\
\hline Paid worker & 11 & 36 \\
\hline
\end{tabular}

Table.2 Physiological workload of pesticide application activity carried out by wearing designed and marketed protective clothing.

\begin{tabular}{|c|c|c|c|}
\hline \multirow[b]{2}{*}{ Physiological Parameters } & \multicolumn{2}{|c|}{ Mean \pm SD } & \multirow[b]{2}{*}{ 't' Value } \\
\hline & $\begin{array}{c}\text { Marketed } \\
\text { Protective Clothing }\end{array}$ & $\begin{array}{l}\text { Designed Protective } \\
\text { Clothing }\end{array}$ & \\
\hline $\begin{array}{l}\text { Average Resting Heart Rate } \\
\left.\text { (b.m- }{ }^{1}\right)\end{array}$ & $76 \pm 3.58$ & $76 \pm 3.58$ & Ns \\
\hline $\begin{array}{l}\text { Average Working Heart } \\
\left.\text { Rate (b.m-1 }{ }^{-1}\right)\end{array}$ & $109 \pm 2.74$ & $105 \pm 4.5$ & $4.2 * *$ \\
\hline $\begin{array}{l}\text { Average Recovery Heart } \\
\left.\text { Rate (b.m- }{ }^{1}\right)\end{array}$ & $90 \pm 5.10$ & $87 \pm 6.89$ & $2.0 \mathrm{Ns}$ \\
\hline Average Peak Heart Rate & $121 \pm 3.49$ & $116 \pm 5.34$ & $4.5 * *$ \\
\hline $\begin{array}{c}\text { Average Energy } \\
\text { Expenditure (kj-m) }\end{array}$ & $9 \pm 0.44$ & $8 \pm 0.73$ & $6.6^{* *}$ \\
\hline $\begin{array}{l}\text { Average Peak Energy } \\
\text { Expenditure (kj-m) }\end{array}$ & $10.5 \pm 0.56$ & $9.72 \pm 0.85$ & $4.4^{*}$ \\
\hline $\begin{array}{c}\text { Average Total Cardiac Cost } \\
\text { of Work }\end{array}$ & $540 \pm 75.13$ & $467 \pm 110.8$ & $2.9 *$ \\
\hline $\begin{array}{c}\text { Average Physiological Cost } \\
\text { of Work }\end{array}$ & $36 \pm 5.05$ & $31 \pm 6.8$ & $3.3^{*}$ \\
\hline
\end{tabular}


Table.3 Comfort level of the marketed and designed pesticide protective clothing

\begin{tabular}{|c|c|c|c|c|}
\hline $\begin{array}{c}\text { Comfort Level of } \\
\text { Pesticide } \\
\text { Protective }\end{array}$ & $\begin{array}{c}\text { Weighted } \\
\text { Mean Score }\end{array}$ & \multicolumn{2}{|c|}{ Frequency percentage } & \multirow{2}{*}{ t Value } \\
\cline { 3 - 5 } & $\begin{array}{c}\text { Marketed } \\
\text { Protective } \\
\text { Clothing }\end{array}$ & $\begin{array}{c}\text { Designed } \\
\text { Clothing } \\
\text { Protective }\end{array}$ & \\
\hline $\begin{array}{c}\text { Somewhat } \\
\text { comfortable }\end{array}$ & $1.00-1.66$ & $5(16.66)$ & - & $2.67 *$ \\
\hline $\begin{array}{c}\text { Comfortable } \\
\text { Highly }\end{array}$ & $1.67-2.33$ & $23(76.66)$ & $24(80)$ & 0.4 \\
\hline $\begin{array}{c}\text { Comfortable } \\
\text { Total Mean score }\end{array}$ & $2.34-3.00$ & $2(6.66)$ & $6(20)$ & 1.75 \\
\hline \multicolumn{2}{|c|}{ Total } & $1.91 \pm 0.26$ & $2.13 \pm 0.25$ & $3.67 * *$ \\
\hline
\end{tabular}

**significant at $1 \%$ level of significance

*significant at 5\% level of significance

Ns= non significant

Table.4 Utility perception of marketed and designed pesticide protective clothing

\begin{tabular}{|c|c|c|c|c|}
\hline $\begin{array}{c}\text { Utility } \\
\text { perception }\end{array}$ & $\begin{array}{c}\text { Weighted mean } \\
\text { score }\end{array}$ & $\begin{array}{c}\text { Frequency percentage } \\
\text { Marketed } \\
\text { protective } \\
\text { clothing }\end{array}$ & $\begin{array}{c}\text { Designed } \\
\text { protective } \\
\text { clothing }\end{array}$ & \\
\hline $\begin{array}{c}\text { Somewhat } \\
\text { useful }\end{array}$ & $1.00-1.66$ & $13(43.33)$ & $2(6.66)$ & $3.7 * *$ \\
\hline Useful & $1.67-2.33$ & $17(56.66)$ & $24(80)$ & $3.2 * *$ \\
\hline Highly useful & $2.34-3.00$ & - & $4(13.33)$ & $0.06 \mathrm{NS}$ \\
\hline \multicolumn{2}{|r|}{ Total Mean score } & $2.02 \pm 0.48$ & $2.33 \pm 0.30$ & $3.1 * *$ \\
\hline
\end{tabular}

$\mathrm{NS}=$ non-significant $\quad * *$ significant at $1 \%$ level of significance

Fig.1 Designed Protective Clothing

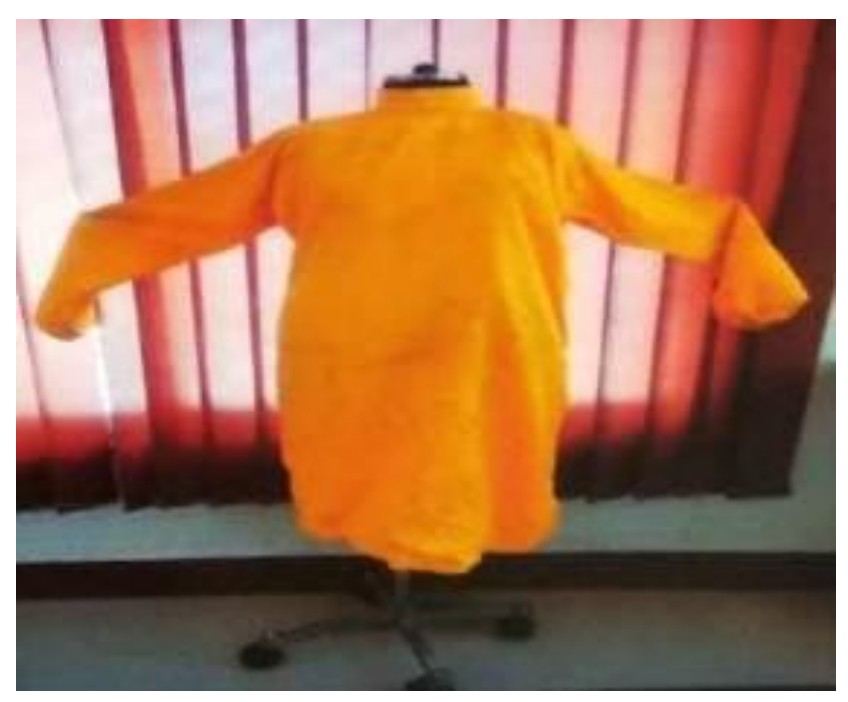


Fig.2 Protective clothing available in local market

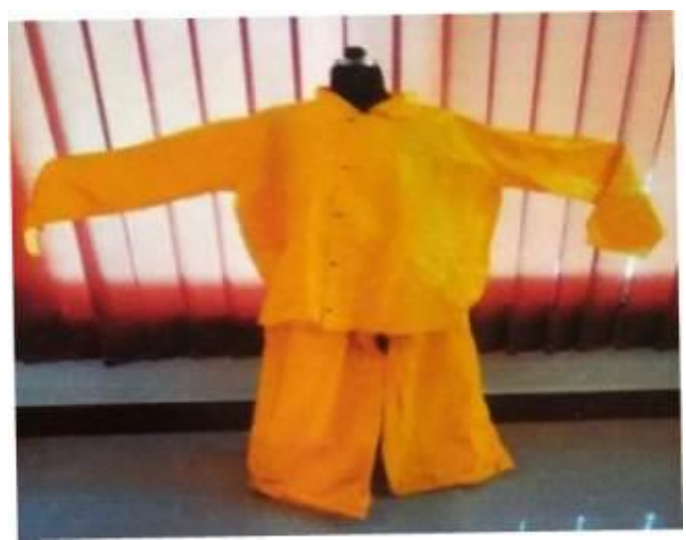

This difference was statistically significant $(\mathrm{t}=3.67 * *)$ indicating that the comfort level of designed protective clothing was significantly higher than the marketed protective clothing while applying pesticides.

\section{Utility perception of marketed and designed protective clothing}

The information regarding utility perception of marketed and designed protective clothing is presented in table 4. It is clear from the table that the higher percentage of the respondents reported marketed protective clothing $(56.66 \%)$ and designed protective clothing $(80 \%)$ as useful. The percentage of the respondents who felt the designed protective clothing as highly useful was 13.33 . The statistically the percentage of pesticide applicants who expressed low level (43.33) of utility was significantly more for marketed protective clothing $\left(\mathrm{t}=3.7^{* *}\right)$ whereas the percentage of the pesticide applicators who expressed medium utility $(80 \%)$ was significantly more for designed protective clothing. The mean score for utility perception was more for designed protective clothing (2.3) than marketed protective clothing (2). These results were proved by statistical significance $\left(\mathrm{t}=3.1^{* *}\right)$. On the whole it was observed that the physiological work load was less when the pesticide application activity was carried out by wearing Designed protective clothing. Comfort level of designed protective clothing was significantly higher than the marketed protective clothing while applying pesticides. The mean score for utility perception was more for designed protective clothing than marketed protective clothing for pesticide application activity.

\section{References}

Boorady L.M., Haise C., Rucker M., Ashdown S.P. (2009) Protective Clothing For Pesticide Applicators: A Multimethod Need Assessment. Jr of Textile and Apparel Technology and Management, Vol.6, Pp: 1-17. https://www.pesticides.montana.edu/re ference/ppe.html-23-2-2021

Pal, S.K. and S.K.Dasgupta, (1996) Pesticide application. Publication by ICRISAT

Sharma,H.L.(2005) Basic Statistical Methods with Applications. Agrotech publishing academy Udaipur PP 304307

Varghese M A, Saha P N, Bhatnagar A, Narayane G G (1994). An acceptable workload for Indian workers. Ergonomics, 22: 1059-1071. 


\section{How to cite this article:}

Madhuri Kulkarni, Jayashree Suryatal and Sunita Kale. 2021. Effect of Designed Protective Clothing on Physiological Workload of Pesticide Application Activity. Int.J.Curr.Microbiol.App.Sci. 10(04): 703-711. doi: https://doi.org/10.20546/ijcmas.2021.1004.071 